\title{
O trabalho feminino sob o olhar estrangeiro Relatório de Mary M. Cannon ao Departamento do Trabalho dos Estados Unidos, 1943
}

\section{Glaucia Cristina Candian Fraccaro}

A pesquisa em fontes históricas produzidas por representantes de países estrangeiros têm sido uma prática muito profícua para os historiadores sociais. Ao mesmo tempo em que essas fontes permitem problematizar o olhar estrangeiro sobre o Brasil, elas revelam aspectos da história do próprio país e fornecem mais elementos para a consolidação de uma perspectiva global da história da classe trabalhadora, capaz de, por exemplo, explicitar as conexões com o imperialismo ${ }^{1}$. Tendo isso em vista, apresento aqui um relatório assinado por Mary M. Cannon, representante Interamericana do Bureau de Mulheres do Departamento do Trabalho, em 1943, sobre o trabalho das mulheres e de menores no Brasil nos estados de São Paulo, Minas Gerais e Rio de Janeiro.

Fundado em 1920, o Bureau de Mulheres (Women's Bureau) tinha como tarefa a formulação de padrões e políticas para promover o bem estar, o sustento das mulheres, assegurar melhores condições de trabalho e desenvolver políticas para garantir os interesses da mulher trabalhadora. $O$ escritório foi criado pelo Departamento do Trabalho (Department of Labor) dos Estados Unidos, órgão que desde 1913 fomenta o desenvolvimento das relações de trabalho e cuida dos direitos dos trabalhadores.

O desenvolvimento industrial da primeira metade do século $X X$, O fortalecimento da classe trabalhadora, e também de uma espécie de elite forjada nessas camadas, proporcionou um debate planetário sobre o trabalho. A fundação da Organização Internacional do Trabalho é resultado desse processo histórico e teve como objetivo concentrar as ideias e políticas que se davam nesse campo. Portanto, passou fazer parte do cotidiano de uma nação que se pretendia imperial que órgãos ligados ao governo dos Estados Unidos compilassem e formulassem informação sobre o mundo do trabalho de diversos países. Significa, portanto, que se tornava comum o

\footnotetext{
* Mestre em História Social pela Unicamp e assistente técnica do Centro Sérgio Buarque de Holanda da Fundação Perseu Abramo. Contato da autora: galufraccaro@gmail.com

${ }^{1}$ Marcel Van der Linden. História do Trabalho: o velho, o novo e o global. Revista Mundo Revista Mundos do Trabalho, v.1, n. 1, (2009), p. 10-26.
} 
envio de representantes a outras nações com o objetivo de captar dados sobre processo de trabalho e o movimento operário.

O relatório de Mary M. Cannon ${ }^{2}$ foi elaborado no ano de 1943 , ao mesmo tempo em que se instituía o programa Labor Attaché, em andamento desde o final da Primeira Guerra Mundial. Tratava-se, então, de um esforço de comunicação intercultural entre os Estados Unidos e demais países que tinha como objetivo trazer aos elaboradores da política internacional norte-americana informações sobre os valores e as aspirações das elites trabalhistas estrangeiras e transmitir a essas lideranças a noção de que se deveria manter uma atitude favorável aos Estados Unidos $^{3}$.

Especificamente, os Labor Attachés deveriam formular informação e propaganda e elaborar uma inteligência econômica, social e política entre as lideranças do mundo do trabalho. Era comum que os relatórios de observadores internacionais passassem pelo Serviço de Informação dos Estados Unidos (United States Information Agency) para serem uniformizados e assim garantirem a integridade da linha de pensamento e da imagem daquele país. A agência era responsável por assegurar o apoio à política internacional dos Estados Unidos e por aconselhar o presidente, 0 pessoal diplomático e os departamentos executivos ${ }^{4}$. Por mais que a instituição do programa de Labor Attachés tenha sido simultânea a elaboração do relatório de Cannon, é possível afirmar que os princípios que norteavam o exercício dos adidos já estavam incluídos na pauta da dirigente do Bureau de Mulheres.

Em linhas gerais, o relatório de doze páginas aborda temas que giram em torno da questão do trabalho das mulheres e das crianças - as profissões mais comuns exercidas pelas mulheres, a atuação delas em trabalhos administrativos e na indústria, os novos postos provocados pela guerra, as condições de trabalho, salários, direito, a organização sindical e em associações e um breve panorama sobre a legislação trabalhista brasileira com destaque especial para a regulamentação do trabalho feminino. Desde 17 de maio de 1932, o trabalho das mulheres passou a ser regulado pelo decreto número 21.417-A que proibia o trabalho noturno ou em atividades insalubres, previa licença para antes e depois do parto, garantia intervalos para trabalhadoras que estivessem em fase de amamentação, a instalação de creches em

\footnotetext{
${ }^{2}$ Pouco foi encontrado acerca da trajetória de Mary M. Cannon: nos anos 1950 ela se tornou chefe da Divisão Internacional do Bureau das Mulheres. Ver: Helen Laville. Cold War Women: The International Activities of America Women's Organizations. Manchester University Press, 2000.

3 Joseph R. Fiszman. The development of administrative roles: The Labor Attaché Program of the U. S. Foreign Service. Public Administration Review, v. 25, n. 3 (Setembro de 1965), p. 203-212.

${ }^{4}$ Ver: http://dosfan.lib.uic.edu/usia/ e http://www.archives.gov/research/guide-fedrecords/groups/306.html Data de acesso, 09 de agosto de 2010.
} 
locais com mais de 30 mulheres e estabeleceu a norma de salário igual para trabalho igual, independente do sexo do trabalhador ${ }^{5}$.

O texto de Cannon é composto por duas partes principais: a primeira divulga suas impressões sobre os temas em questão com o objetivo de publicá-las; a segunda, é classificada como "Confidencial" e traz opiniões que, supostamente, não poderiam vir à público, talvez, por revelar de forma mais direta os objetivos da participação da observadora internacional, como veremos adiante.

Mary M. Cannon visitou treze fábricas nas cidades de São Paulo, Rio de Janeiro e Juiz de Fora e com base nas suas observações e entrevistas com funcionários ligados ao Ministério do Trabalho, Indústria e Comércio ela elaborou o texto que se segue. Em termos gerais, Cannon aponta as péssimas condições de trabalho nas fábricas brasileiras revelando seus critérios de racionalização do trabalho que, na visão da observadora, o Brasil parecia estar longe de atingir.

Cannon parte da ideia de que há ocupações típicas às mulheres, como a enfermagem e o serviço social e que, é por causa da guerra que elas são impelidas a novos papéis e novos postos de trabalho, inclusive na indústria. Curiosamente, a observadora também registra que essas mulheres trabalham para garantir seu sustento e de suas famílias e que não estavam em busca apenas de obterem independência econômica. Cannon se surpreendeu com a carestia do Brasil face à realidade norte-americana e o movimento feminista, conhecido por ser uma organização de mulheres de classe média em luta por emancipação e direitos civis. Ao se valer da confidencialidade do texto, a representante problematiza a falta de oportunidades para as mulheres, a resistência em promovê-las e falta de interesse em investir em especializações profissionais. Ela também considera que o Departamento Nacional do Trabalho se omite ao permitir que seja difundida a noção de que mulheres exercem trabalhos "mais fáceis" e portanto, recebem menores salários.

A representante do Departamento do Trabalho se dedicou também a explicar o aparato estatal montado a proteger o trabalho no Brasil. Descreveu que os trabalhadores estão organizados em sindicatos que, por sua vez, são controlados pelo Estado. Contou que o Departamento Nacional do Trabalho brasileiro tem jurisdição sob os estaduais, com exceção de São Paulo, e que as várias divisões como a inspeção e a seção de mulheres funcionavam apenas no Distrito Federal. Os inspetores e funcionários reclamam com frequência que faltava dinheiro e pessoal para desempenhar todas as funções determinadas pela lei.

\footnotetext{
${ }^{5}$ Decreto n. 21.417-A, de 17 de maio de 1932 regula as condições do trabalho das mulheres nos estabelecimentos industriais e comerciais. De agora em diante, será citado como Decreto do Trabalho Feminino.
} 
Para Cannon, a regulamentação do trabalho feminino poderia significar não apenas a proteção das mulheres no mundo do trabalho, mas também certa desvantagem diante do trabalhador masculino na ordem liberal. A forma como o Decreto do Trabalho Feminino se aplicava no cotidiano da mulher trabalhadora passou a ser investigada pelos tribunais brasileiros do trabalho. Dessa forma, a representante revela que a legislação a respeito do trabalho da mulher pode ter se dado em termos até mesmo paradoxais e que, certamente, mereceria um esforço de pesquisa maior. Por exemplo, um líder sindical dos têxteis chega a afirmar que as trabalhadoras não estão nas fileiras dos sindicatos porque já estão contempladas com a proteção do trabalho pelo estado. Surpreende que a observadora ofereça exemplos de sindicatos que contam com alta participação de mulheres, como as telefonistas de São Paulo e as trabalhadoras têxteis do Rio de Janeiro.

A participação das mulheres nem poderia ser medida exclusivamente pela presença nos sindicatos ${ }^{6}$. Jandyra Rodrigues, chefe da repartição de mulheres do Departamento Estadual do Trabalho de São Paulo, contou à Cannon que as trabalhadoras procuram com muita frequência o escritório e que por isso teria que aumentar a prestação de serviços, indício de que poderia haver uma consciência sobre as leis entre algumas trabalhadoras por fazerem uso do aparato do estado para garantir direitos. Além disso, a representante norte-americana relata que as mulheres também estavam organizadas em entidades que pertenciam à Federação Brasileira pelo Progresso Feminino e outras associações ligadas à Igreja Católica.

O relato de Cannon, além de propiciar uma cuidadosa análise sobre a situação do trabalho de mulheres e de menores no Brasil do período, demonstra os interesses que os observadores internacionais tinham ao investigar o tema no país. Ela revela que as entrevistas e os levantamentos realizados junto às lideranças do mundo do trabalho e os funcionários públicos forneceram ao Departamento do Estado dos Estados Unidos um quadro detalhado sobre as questões de maior interesse às lideranças locais. A representante endereça ao escritório os nomes, as ocupações e os temas sobre os quais essas lideranças se debruçam, como por exemplo, os novos cargos que as mulheres podem ou não assumir na indústria. Esse quadro permite que o órgão estrangeiro forneça material específico e direcionado e assim cumpra, de forma mais produtiva, a tarefa de influenciar essas lideranças em prol do projeto americano.

\footnotetext{
${ }^{6}$ Para além dos sindicatos, formas diversas de compartilhar identidades e de organização de trabalhadores já foram discutidas por Claudio Batalha. O Movimento operário na Primeira República. Rio de Janeiro: Jorge Zahar Editor, 2000 e por Leonardo Miranda, "E o Rio dançou - Identidades e tensões nos clubes recreativos cariocas (1912-1922)", In: CUNHA, M. C. (e outros) Carnaval e outras f(r)estas Ensaios de História Social da Cultura, Campinas: Editora da UNICAMP, 2002.
} 
As informações compiladas pela observadora também contém algumas sugestões de procedimento ao Departamento - ela aponta nomes de mulheres de destaque do aparato governamental que devem ser enviadas para viagens de campo aos Estados Unidos evidenciando uma prática comum ao envolvimento daquele país em assuntos sindicais brasileiros, formalizado durante os anos do pós-guerra ${ }^{7}$.

Escrito originalmente em inglês, uma cópia encontra-se sob a guarda da Organização Internacional do Trabalho, na sede em Genebra, de onde foi reproduzido ${ }^{8}$. Até onde pude investigar, a publicação do relatório sobre o Brasil ao Departamento do Trabalho dos Estados Unidos é inédita ${ }^{9}$. A tradução foi feita diretamente do documento que parece ter sido escrito com alguma pressa por apresentar frases aparentemente incompletas. Todas as notas inseridas no texto a seguir são notas da tradutora e não fazem parte do texto original.

\footnotetext{
${ }^{7}$ WELCH, Clifford Andrew. "Internacionalismo trabalhista: o envolvimento dos Estados Unidos nos sindicatos brasileiros, 1945-1964". Perseu: história, memória e política, (2009), n. 3, p. 185-219.

${ }^{8}$ Relatório contido na pasta Legal Status of Women - Equal pay for Equal Work, Latin America - WN 686, Biblioteca do International Labor Office, Genebra, Suíça.

${ }^{9}$ Por ora, encontrei apenas uma citação do referido relatório no artigo de Julia Flanigan SUGGS, Julia Flanigan. "Women Workers in Brazil". Phylon [Clark Atlanta University], v. 8, n.1, 1947, p. 60-67.
} 
Departamento do Trabalho dos Estados Unidos

Bureau de Mulheres

Washington

BREVE SUMÁRIO DE RELATÓRIOS SOBRE O BRASIL

(Rio de Janeiro, Minas Gerais, São Paulo)

Incluindo análise de problemas e sugestões por

Mary M. Cannon, Representante Interamericana do Bureau de Mulheres do

Departamento do Trabalho, Agosto de 1943

Este resumo confidencial de observações e sugestões, baseado em relatórios detalhados enviados ao Bureau de Mulheres do Departamento do Trabalho dos Estados Unidos durante minha estadia no Brasil, é destinado apenas à atenção dos responsáveis pela política oficial e pelo programa de cooperação Interamericano. Um boletim para distribuição pública, que fornecerá mais dados econômicos e sociais dos que os aqui apresentados, está em preparação.

\section{A MULHER NAS (E AS) PROFISSÕES}

As faculdades profissionalizantes das universidades brasileiras admitem mulheres há alguns anos. Não há duvidas de que mais mulheres têm conquistado diplomas profissionais do que têm oferecido, por outro lado, um curso geral e similar a nossa Liberal Arts Colleges. A organização das Escolas de Filosofia e Letras na universidade (artes liberais) é um recente progresso.

A universidade treinou mulheres que, evidentemente, encontraram obstáculos comuns na prática de suas profissões e há um número surpreendente de mulheres com sucesso profissional. Engenheiras, médicas, advogadas, químicas, professoras galgaram espaço por si mesmas, tanto no trabalho privado quanto no serviço público. Uma jovem foi recentemente nomeada procuradora da União e outras têm cargos semelhantes em vários estados; outra é diretora de ensino secundário, uma mulher é diretora do Museu Nacional e uma médica foi eleita no ano passado para a Academia Nacional de Medicina. Mulheres profissionais têm se destacado como excelentes voluntárias em órgãos de defesa civil desde a guerra, fornecendo voluntariamente suas habilidades especiais.

TRABALHO SOCIAL 
As importantes escolas de Serviço Social localizadas no Rio de Janeiro e em São Paulo tem orientação católica. Os estudantes que lá se formam são empregados principalmente em hospitais, centros de saúde, institutos de bem-estar da criança, associações de caridade e na Secretaria de Estado da Previdência Social. Atualmente, os assistentes sociais têm o objetivo de elevar o estatuto profissional do trabalho social, especialmente em termos de melhores salários. A atitude anterior era a de que os trabalhadores sociais, por serem interessados em ajudar a humanidade, não deveriam se preocupar com salários mais elevados ou maior reconhecimento profissional. A Escola de Serviço Social pretende alargar o âmbito do trabalho social colocando os recém-formados para trabalhar nas fábricas, mas tem sido difícil despertar o interesse dos estudantes neste novo campo. Foi solicitado o envio de material impresso para ajudar na formação industrial de assistentes sociais, incluindo dados sobre a saúde e a segurança das mulheres nas indústrias, os tipos de trabalho [em] que as mulheres podem ser empregadas e os problemas com o pessoal relacionados à presença de mulheres na indústria.

\section{ENFERMAGEM}

A prática da enfermagem ainda não alcançou um status profissional e, como sempre, tem sido e, ainda é, considerada um trabalho servil. A situação é comparável à dos Estados Unidos na virada do século. Uma dupla tarefa precisa ser feita para levar o ofício da enfermagem para seu estatuto de direito: as condições de trabalho devem ser melhoradas e os critérios para eleger as candidatas devem ser mais rigorosos a fim de atrair um tipo mais elevado de meninas para o treinamento. Há um esforço em curso agora para melhorar o nível profissional de enfermagem. A Escola de Enfermagem da nova Faculdade de Medicina Hospital em São Paulo, este ano, teve 80 alunos selecionados dentro de número ainda maior de candidatos. Escola de Enfermagem Ana Nery, no Rio de Janeiro, tem melhorado a qualidade de seus cursos e normas.

\section{MULHERES NOS ESCRITÓRIOS}

Um grande número de mulheres trabalhava para o governo e em outros escritórios. O DASP ${ }^{10}$, que é um serviço público federal, pratica a igualdade de oportunidades (pelo menos teoricamente) para homens e mulheres. As mulheres têm ocupado habilmente cargos de responsabilidade no serviço público. Três agências federais, recentemente, fecharam suas portas para novos postos às mulheres. Algumas mulheres afirmam que muitas delas têm se saído melhor que os homens em concursos públicos e que, por isso, os homens estão tentando impedir que elas disputem os empregos mais bem pagos.

\section{A MULHER NA INDÚSTRIA}

\footnotetext{
${ }^{10}$ O Departamento Administrativo ao Serviço Público (DASP) foi criado pelo Decreto-Lei n. 579 de 30 de julho de 1938, era um órgão ligado diretamente subordinado à presidência da República e tinha por objetivo organizar repartições, departamentos e estabelecimentos públicos. Em 1986, ele foi extinto e substituído pela Secretaria de Administração Pública da Presidência da República.
} 
O desenvolvimento industrial do Brasil desde a Primeira Guerra, e também nos dias de hoje, com a presente guerra, é um fato bem conhecido. É importante ter em mente que as cinco principais indústrias do país, de acordo com dados oficiais do governo brasileiro (têxtil, produtos alimentícios, vestuário, produtos químicos e metalurgia) são também as indústrias que mais empregam mulheres. As mulheres são empregadas cada vez em mais de metade das indústrias pequenas e em expansão no Brasil. A nova indústria aeronáutica e a de produtos pastosos empregam mulheres, uma fábrica de desidratação de alimentos em Santos, que tem planos para expandir. 0 cultivo da seda e sua manufatura em estabelecimentos do Estado de São Paulo absorvem amplamente a mão de obra feminina e mais mulheres serão necessárias para que a indústria continue a se desenvolver. A indústria da seda no Brasil fornece apenas uma percentagem pequena da demanda doméstica e agora, em Março de 1943, não tinha sido capaz de produzir a quantidade necessária para a exportação. No momento, as mulheres não ocupam, de forma considerável, cargos de direção em outras indústrias do país tais como a fabricação de máquinas (máquinas de café e de processamento de arroz, máquina operatriz, vagões, máquinas agrícolas), produtos de papel, madeira e mobiliário, materiais de construção, etc.

O Brasil, como outros países sul-americanos está aumentando seu comércio estrangeiro e também faz negócios com o Norte e o Sul da África. Grandes exportações de algodão são enviadas para a África e outros países da América do Sul. "Em 1942, a produção das fábricas de São Paulo aumentou de 40 a 50 por cento em comparação com os anos anteriores. A produção interna de gêneros têxteis está consolidada e melhorando a qualidade e os industriais estão otimistas quanto ao futuro, especialmente no que diz respeito à exportação de fio de algodão", de acordo com o Foreign Commerce Weekly de 10 de abril, trata-se de uma indústria que emprega. Uma das mais antigas fábricas no Brasil, localizada em Juiz de Fora, emprega mulheres na produção desde que começou.

Não há dúvida de que a grande maioria das mulheres empregada pelo setor industrial trabalha por necessidade e não para obter ganhos extras, nem para conseguir independência econômica. Elas ajudam a sustentar a família ou ainda elas são a única fonte de salário para si e para seus filhos. Nas fábricas de algodão, especialmente, há uma atmosfera de apatia, na maioria desses estabelecimentos, mulheres e meninas nas máquinas estavam mal vestidas e, muitas vezes, descalças.

Além das 13 fábricas têxteis, foram feitas visitas a outras, incluindo estabelecimentos do setor de processamento alimentício, farmacêutico, fumo, eletrodomésticos, gráfico, confecção de vestuário, lingeries, chapéus, plásticos, metalúrgica de aeronaves, tapete, cultivo da seda e telefônico.

\section{A POSIÇÃO DA MULHER NA INDÚSTRIA}

As mulheres ocupam em grande parte, o chamado "serviço fácil" que exige pouco esforço físico e curto tempo de aprendizagem. Já que o trabalho delas é considerado como "serviço fácil" a remuneração é baixa (Existe uma lei federal que estabelece salário mínimo). Há pouca oportunidade para a capacitação profissional ou treinamento para postos mais qualificados.

Algumas mulheres jovens são empregadas em escritórios, algumas delas são supervisoras. As mulheres também são empregadas em um laboratório de uma fábrica 
de algodão que foi visitada; elas estavam trabalhando em postos que exigem destreza das mãos, atenção, precisão, inteligência e algumas delas estavam conduzindo máquinas, são poucas as químicas nas empresas farmacêuticas.

\section{NOVOS POSTOS DE TRABALHO PROVOCADOS PELA GUERRA}

Algumas fábricas estão usando um pequeno número de mulheres em postos que tradicionalmente pertenciam aos homens: na paragem das máquinas, como mecânicas de máquinas, nas torres de operação, soldadoras numa fábrica de aviões e como desenhistas de projetos. A Estrada de Ferro Central ofereceu cursos de formação emergenciais para várias centenas de mulheres. Elas foram empregadas como telegrafistas e operadoras de telefonia. O Bureau da Mulher enviou, para os gerentes de algumas fábricas, material a respeito dos trabalhos que a mulher pode desempenhar.

Sem dúvida, haverá mais mulheres empregadas com o avançar da guerra, já que um novo decreto ${ }^{11}$ obriga os empregadores a pagar metade do salário do empregado para sua família quando ele é convocado para o serviço militar. Consequentemente, algumas fábricas não substituirão os postos de homens com os outros homens.

\section{CONDIÇÕES}

Nas fábricas de algodão, vários esforços têm sido feitos para melhorar as condições de ventilação e limpeza, mas na maioria dos estabelecimentos visitados foram encontrados poeira e fiapos e o piso não estava limpo.

Nas fábricas têxteis, as cadeiras não são fornecidas, exceto quando o trabalho executado a demanda e praticamente não há boas cadeiras com encostos apropriados. O mesmo não acontece em outras indústrias como, por exemplo, na farmacêutica.

As instalações sanitárias não estavam à mostra, as portas dos toaletes de algumas fábricas chegam a ser ofensivas. Há poucos vestiários.

A luz artificial para o trabalho desempenhado perto dos olhos é geralmente deficiente.

Pouca atenção tem sido dada ao uso de dispositivos de segurança e ao ensino de métodos de prevenção de acidentes.

Que melhores condições refletem melhor a atitude e a aparência dos trabalhadores, e que as mulheres respondem à educação sobre a aparência pessoal e em manter as instalações sanitárias limpas está provado pelo que foi realizado em estabelecimentos tais como a Fábrica de Alpargatas e a Johnson \& Johnson em São Paulo.

Em outras indústrias, há também algumas fábricas com condições de trabalho muito boas, como por exemplo, uma fábrica de lingeries de seda em Juiz de Fora, a fábrica MASDA no Rio de Janeiro e indústrias farmacêuticas, tanto do Rio de Janeiro como de São Paulo.

\section{SALÁRIOS}

${ }^{11}$ Trata-se do Decreto-Lei n. 5.612, de 24 de junho de 1943. 
O salário mínimo se aplica a homens e mulheres. O sistema de empreitadas é geral. Os salários são baixos, mas há relatos de que estão muito melhores do que antes do estabelecimento do salário mínimo.

Nos termos da legislação vigente, o empregador que fornece creche e instalações para as mães amamentarem seus bebês pode deduzir $10 \%$ dos salários de todas as mulheres trabalhadoras. A legislação trabalhista está sob revisão e foi proposta a supressão dessa cláusula.

\section{MENORES}

Os menores que tem entre 14 e 18 anos podem ser empregados em indústrias em postos não prejudiciais à saúde se tiverem um certificado de trabalho, aqui chamado de "Carteira". Para garantir isso, eles devem apresentar uma certidão de nascimento ou documento substituto legal, autorização, um atestado médico de capacidade física e mental e comprovar as competências de ler, escrever e fazer aritmética simples.

Outra cláusula da lei do salário mínimo permite que os menores que têm entre 14 e 18 anos recebem salários inferiores ao mínimo de adultos. O salário pago os menores não pode ser inferior a $50 \%$ do salário mínimo estabelecido para os adultos. Nem todas as empresas aproveitam esse dispositivo e pagam o mesmo valor tanto aos menores como aos adultos. Outras utilizam uma escala de graduação, por meio da qual o montante pago aos menores é o de até $80 \%$ da tarifa de adulto. As estatísticas não estão disponíveis, mas todos os entrevistados afirmaram que um número maior de menores está sendo empregado agora do que no passado, embora, esta lei e sua aplicação tenham provocado certo aumento da faixa etária de menores trabalhando. Certa preocupação foi expressa com relação à prática de algumas fábricas, lojas e escritórios - despedir os menores assim que completam a idade de 18 anos com o objetivo de evitar o pagamento do salário de adulto.

Para os menores trabalhadores devem ser proporcionadas, dentro de determinadas circunstâncias, aulas educativas e para aprendizes. Algumas fábricas apresentam bons sistemas educacionais.

\section{CRECHES, ETC.}

Algumas fábricas possuem creches (que são exigidas pela lei) para as mães poderem levar seus bebês para amamentar. Esses estabelecimentos cuidam de crianças de 3 a 5 anos e é comum possuírem equipamentos e um funcionário fornecidos pela própria empresa. Alguns deles têm instalações para dar banho e alimentar os bebês. As creches com um funcionário são exigidas por lei para cada estabelecimento em que trabalhem pelo menos 30 mulheres acima de 16 anos de idade.

\section{MULHERES NOS SINDICATOS}

As organizações de trabalhadores, chamados de "sindicatos", são controladas pelo governo e devem ser registradas junto aos Departamentos do Trabalho. Os sindicatos também devem possuir estatutos próprios e oficiais aprovados e quaisquer queixas graves são negociadas por meio dos Departamentos, que tem uma divisão 
especial para lidar com os assuntos relacionados aos sindicatos. As greves são proibidas. O diretor do Departamento do Trabalho de São Paulo afirmou que o atual chefe do Conselho Nacional do Trabalho depois de passar algum tempo na Itália, copiou a organização do trabalho do país e aplicou no Brasil. Um pequeno imposto é cobrado sobre o salário de todos os trabalhadores, que é uma contribuição para o sindicato no qual seu trabalho se inclua. A adesão é voluntária e as mensalidades podem ser deduzidas diretamente do salário, se for a vontade do sindicato ou podem ser recolhidas por um agente.

A lei exige que os fundos acumulados pelo imposto sindical sejam utilizados em serviços de saúde, cooperativas e projetos educacionais.

Dr. Vascos Andrade, do Departamento do Trabalho de São Paulo, chefe da divisão dos sindicatos, disse que a adesão às entidades "não é tão grande como deveria ser, por exemplo, apenas 2.000 dos 50.000 trabalhadores têxteis são membros do sindicato da categoria".

Em números relativos, um pequeno número de mulheres está nos sindicatos. Um jantar foi realizado para mim no Rio de Janeiro por representantes sindicais e a única mulher empregada presente trabalhava numa loja de departamento, que não possui sindicato. No outro dia, as entidades, encorajadas pelo diretor do Departamento do Trabalho, aproveitaram a ocasião da minha visita para fazer uma declaração de solidariedade aos trabalhadores dos Estados Unidos ao Sr. Caffrey, embaixador dos Estados Unidos no Brasil. Não havia mulheres presentes.

$O$ representante do sindicato têxtil do Rio de Janeiro disse que as mulheres estavam protegidas, que não precisavam lutar por seus direitos como trabalhadoras. A atitude de indiferença da maioria das mulheres que trabalham nas fábricas têxteis reflete esta afirmação.

Há um ativo sindicato de mulheres que trabalham numa companhia telefônica em São Paulo que faz oposição ao sindicato da companhia. Elas ajudaram a organizar o sindicato em Santos. Há também um sindicato composto por parteiras em São Paulo.

O sindicato de trabalhadores têxteis no Rio de Janeiro tem 6.000 membros, estima-se que um quarto deles são mulheres. A participação nas reuniões é de cerca de 600 pessoas e, delas, cerca de 100 são mulheres. Quando perguntado o que é feito nessas reuniões a resposta foi: "Apresentar relatórios financeiros, explicar as leis trabalhistas, os direitos e deveres dos trabalhadores". Novamente perguntado se são trazidas queixas para o sindicato, eles responderam: "Sim, o sindicato é o intermediário". A mesma observação foi feita por um empregado de escritório no Rio de Janeiro.

\section{LEGISLAÇÃO PARA AS MULHERES NA INDÚSTRIA}

A legislação para as mulheres trabalhadoras na indústria tem sido amplamente protetora, talvez à custa de ganhos e progresso. A primeira cláusula em relação às mulheres, diz que os mesmos salários, independentemente do sexo do trabalhador, serão pagos por trabalho de igual mérito. "Há algumas dúvidas na mente de alguns advogados sobre se o decreto está sendo efetivo. Por uma questão prática, os tribunais trabalhistas estão ouvindo casos deste tipo, determinando em cada caso, se o trabalho das mulheres é ou não de tipo semelhante ao do trabalhador masculino, autorizando-a, ou não, a receber salário igual para trabalho igual". (Retirado do 
relatório do Sr. Giardino, que fez um levantamento para a Divisão de Normas Trabalhistas).

As disposições quanto à maternidade garantem à mulher quatro semanas de repouso, antes e após o parto. Ela deve receber um benefício-maternidade igual a metade do seu salário, calculado com base nos ganhos dos últimos seis meses e com o direito de regressar ao seu trabalho. Se a mulher não se enquadra a receber a metade do seu salário proveniente de fundos de segurança social, o empregador deve pagá-la. (O período de repouso antes e depois do parto pode ser prorrogado por duas semanas, se certificado por um médico).

Cada estabelecimento, que emprega pelo menos 30 mulheres com mais de 16 anos de idade deve fornecer acomodações adequadas onde as mães possam deixar seus filhos, até o momento de desmamar, aos cuidados de alguém capaz de cuidar. 0 período habitual é de um ano. A mãe deve ter direito a dois períodos de descanso de meia hora para cuidar do seu bebê durante os primeiros seis meses de vida dele.

Os empregadores que fazem estas disposições com relação ao cuidado da criança podem, de acordo com a lei, deduzir $10 \%$ do salário mínimo de todas as mulheres na fábrica. A legislação trabalhista está sob revisão e foi proposta a supressão dessa cláusula.

O trabalho noturno, entre 22 horas e 5 horas, é proibido, mas permissões podem ser concedidas em casos excepcionais. Está excluído da proibição o trabalho em hospitais, em instituições e em centrais telefônicas.

Levantar materiais pesados é proibido, assim como também é o trabalho que é perigoso e insalubre.

As leis que regulamentam a jornada de trabalho se aplicam a mulheres e homens.

\section{DEPARTAMENTOS DO TRABALHO}

O Departamento Nacional do Trabalho ${ }^{12}$ faz parte do Ministério do Trabalho, Indústria e Comércio, está instalado num novo e bonito prédio no Rio de Janeiro e, aparentemente, tem espaço para experiências. No começo do ano de 1943, um novo plano de organização foi aprovado, entre outras mudanças, a divisão de saúde e segurança foi reforçada e a divisão de mulheres e crianças foi alterada para a inspeção de saúde e segurança.

No meu entendimento, o sistema elaborado pelo diretor do Departamento Nacional do Trabalho tem jurisdição sobre os departamentos estaduais ${ }^{13}$ (com exceção

\footnotetext{
${ }^{12}$ O Departamento Nacional do Trabalho foi criado pelo Decreto o 3.550 , de 16 de outubro de 1918, com o objetivo de regulamentar a organização do trabalho no Brasil. Em 1923, foi criado o Conselho Nacional do Trabalho que tinha como tarefas fiscalizar o trabalho e a remuneração nas indústrias, os contratos de trabalho, os sistemas de conciliação e arbitragem, o trabalho de menores e mulheres, acidentes, seguros, caixas de aposentarias, pensões e créditos. Ver: Samuel Fernando de Souza. Coagidos ou Subornados - trabalhadores, sindicatos, Estado e as leis do trabalho nos anos 1930. (Tese de doutorado em História Social do Trabalho), Instituto de Filosofia e Ciências Humanas, Universidade Estadual de Campinas, 2007, p. 30.

${ }^{13}$ Departamentos Estaduais do Trabalho. Em 1932, assumiu o Ministério do Trabalho Indústria e Comércio Joaquim Pedro Salgado Filho que criou as Inspetorias Regionais do Ministério do Trabalho, Indústria e Comércio, por meio dos Decretos n. 21.690 e 23.288, de 10 de agosto de 1932 e 26 de outubro de 1933, respectivamente.
} 
do Estado de São Paulo ${ }^{14}$ ), mas as várias divisões tais como a inspeção e a seção de mulheres e crianças funcionam apenas no Distrito Federal.

As seções voltadas para as mulheres e crianças nos Departamentos do Trabalho tem se ocupado com a grande quantidade de trabalho envolvendo a elaboração de licenças de trabalho para os menores e teve muito pouca oportunidade, por ter equipes reduzidas, de fazer mais para melhorar os padrões de trabalho aplicando as leis existentes. Eles aproveitaram a oportunidade da visita para conhecer mais sobre o que foi feito nos Estados Unidos por meio da aplicação da lei e da educação de empregadores com o objetivo melhorar as condições de trabalho para as mulheres.

A Chefe da Seção de Mulheres e Crianças no Rio de Janeiro trabalhava, anteriormente, no escritório de contabilidade do Ministério do Trabalho e foi transferida no final do ano de 1942. Ela é uma boa administradora, tem personalidade atraente e está interessada em seu trabalho. A seção, no momento da minha visita, tinha apenas duas mulheres que faziam inspeções nos estabelecimentos de trabalho. A chefia da seção cuidava da quantidade enorme de trabalho que envolvia a preparação das carteiras de trabalho para menores de idade de 14 a 18 anos. As queixas relativas a menores também são direcionadas a esta divisão.

O Departamento do Trabalho do Rio de Janeiro e de outros locais visitados colocaram suas instalações a minha disposição, providenciaram visitas às fábricas e outras visitas, responderam a perguntas e debaterem algumas questões comigo. A segurança e a saúde foram recentemente objeto de melhorias necessárias. Eu sugeri ao Diretor do Departamento de Educação do DASP que organizasse cursos para inspetores de fábrica. O material foi enviado por nosso escritório, e de acordo com uma carta recebida recentemente, foi usado.

Em Belo Horizonte, capital de Minas Gerais, há um Departamento do Trabalho muito bem organizado (responsabilidade do departamento federal do qual recebe fundos e está subordinado). Em janeiro, havia 30 funcionários e a nomeação de seis novos inspetores foi anunciada. Aqui, como em outros lugares, às vezes, as nomeações são influenciadas pela política e pela amizade, mais do que pelas qualificações pessoais. O diretor do departamento, em Belo Horizonte, afirma que não tem pessoal suficiente para fazer todo o trabalho e que "o Departamento Nacional do Trabalho faz leis e regulamentos novos, mas não nos dá a estrutura necessária". Uma jovem mulher foi convidada pelo diretor do Departamento Nacional a ir a Belo Horizonte para organizar as seções de mulheres e crianças, mas até o momento da minha visita, ela estava trabalhando nas reclamações de acidentes. Ela é eficiente, atraente, inteligente e está interessada em fazer mais do que apenas um trabalho de rotina. $O$ diretor ainda disse que os inspetores não recebem nem um salário, nem diárias suficientes para cobrir despesas quando eles precisam ir a outros lugares para fazer as inspeções. 0 CNT paga a diária de cinco cruzeiros para as despesas, mas o custo do hotel mais barato é de dezesseis cruzeiros. Essa mesma reclamação foi ouvida em São Paulo e, de fato, parece ser verdadeira para todos os países visitados.

\footnotetext{
${ }^{14}$ O Departamento Estadual do Trabalho de São Paulo teve uma trajetória diferente dos demais departamentos regionais. O órgão existia desde 1911 e refletiu boa parte das tensões políticas entre o governo federal e o estado de São Paulo resultando numa relação particular com o Ministério do Trabalho, Indústria e Comércio. Ver: Marcelo Antonio Chaves. A trajetória do Departamento Estadual do Trabalho de São Paulo e a mediação das relações de trabalho (1911-1937). (Tese de Doutorado em História Social). Instituto de Filosofia e Ciências Humanas, Universidade Estadual de Campinas, 2009.
} 
O Departamento Estadual do Trabalho (DET) em São Paulo é o maior e melhor organizado. São Paulo é o centro industrial do Brasil. O DET empenhou-se na seção de mulheres e crianças, na divisão de organizações de trabalhadores, para os registros das mulheres necessários para cartões de identificação e na divisão de relatórios e registros do emprego.

A seção de mulheres e crianças faz parte da divisão de inspeção. A chefe atual, Jandyra Rodrigues, trabalhou na inspeção antes de ser chefe da seção em 1940. A repartição fornece licença para 200 mil crianças com idades entre 14 e 18 anos em São Paulo, atualmente nos arquivos. São apresentadas entre 400 e 450 pedidos de autorização por dia. Esta seção conta com 26 empregados, 8 dos quais são inspetores. A menos que as fábricas sejam grandes, um inspetor chega a fazer três visitas por dia. Jandyra Rodrigues diz que os [baixos] salários pagos aos inspetores tornam difícil não só recrutar pessoas com a prática e experiência que deveriam ter como também mantê-los nos postos depois de treinados. Ela acompanha o trabalho da equipe muito de perto e exige um bom trabalho, inclusive aos inspetores de fora da cidade de São Paulo. A chefe da seção é muito competente e uma administradora eficiente. Ela está, em todos os seus aspectos, preocupada com o problema das crianças que trabalham e tem bons planos para o futuro. As mulheres vêm a esta repartição com muitas queixas e para pedir ajuda e, por isso a Rodrigues pretende aumentar o atendimento da sua seção de mulheres na indústria.

Várias das visitas às fábricas foram feitas com a presença de inspetor da Divisão de Inspeção.

A Secretaria de Estado da Saúde de São Paulo tem uma seção de Higiene Industrial que tem uma equipe de 12 médicos e 20 outros funcionários que fazem as inspeções de segurança e saúde. O diretor, que pode ter uma opinião tendenciosa, orientou aos inspetores do Ministério do Trabalho que fiscalizassem salários, horários, etc, e que não haveria necessidade de entrar nas fábricas, pois eles podem obter as informações necessárias dos escritórios dele.

O Departamento Estadual do Trabalho do Rio de Janeiro tem uma boa divisão de estatística, que também edita um boletim mensal sobre trabalho.

\section{PROGRAMA DE APRENDIZAGEM}

A indústria no Brasil tem dificuldades em contratar mecânicos qualificados e técnicos. O SENAI (Serviço Nacional de Aprendizagem Industrial) é direcionado a esta necessidade e para dar aos jovens (principalmente meninos) formação de habilidades específicas. O novo programa do SENAI estava sendo criado no momento da visita, entre os meses de dezembro e janeiro. Um número de escolas profissionais com cursos técnicos funcionaram durante alguns anos. Os diretores do programa SENAI do Rio de Janeiro e de São Paulo solicitaram ao Bureau da Mulher estudos e boletins sobre os tipos de trabalhos que as mulheres podem desempenhar nas indústrias de guerra e a respectiva formação necessária.

O programa é financiado por um imposto, a "contribuição obrigatória", paga pelo empregador sobre a folha de pagamento. Os recursos provenientes desse imposto são administrados pelas organizações patronais de diferentes indústrias. 0 Comitê Nacional é formado por representantes de organizações patronais, do Ministério da Educação e do Departamento do Trabalho. 
O número de aprendizes em cada fábrica tem que ser igual a $5 \%$ dos trabalhadores qualificados e, para isso, serão utilizados testes na seleção de candidatos para o treinamento. Ter ensino básico ou primário completo é um requisito. Um escritório de emprego vai funcionar como parte do SENAI. São Paulo deverá ter dois especialistas em orientação profissional que vai trabalhar especialmente com meninos e meninas que não conseguem encontrar o trabalho para os quais possuem aptidão. Um terço do tempo de treinamento será de três a quatro anos.

Cursos de emergência para adultos serão organizados na Escola Nacional de Vocação Profissional e bons trabalhadores são treinados dentro das fábricas.

O programa é voltado quase exclusivamente para meninos. O SENAI de São Paulo planeja ministrar cursos para as meninas para ensinar o ofício de tecelã e fiandeira em fábricas têxteis. Eu sugeri que eles enviassem um professor para os Estados Unidos para estudar as ocupações em que as mulheres aqui são empregadas e para participar de cursos de formação. Um recorte de um jornal carioca mostra que o compromisso foi feito.

Algumas fábricas têm cursos voltados para os menores que ainda não tenham terminado a escola primária e também cursos de aprendizes. Por exemplo, as ferrovias de São Paulo têm cursos muito bons para aprendizes com duração de três ou quatro anos e uma fábrica têxtil em Bangu promove um curso de dois anos de duração para aqueles que tenham concluído o ensino primário, e um de três anos para aqueles que não terminaram. O tempo de trabalho pode ser usado para frequentar as aulas.

\section{A ORGANIZAÇÃO DE MULHERES}

Por muito tempo, as mulheres brasileiras trabalharam em entidades de caridade e organizações educacionais e têm desenvolvido responsabilidades importantes tanto administrativas quanto financeiras. Há uma tendência crescente entre os grupos organizados de mulheres semelhante a dos Estados Unidos. Algumas organizações de mulheres têm projetos para as meninas e mulheres que trabalham. Uma organização cuja fundadora apresentou um projeto ao Congresso, em 1937, solicitando a criação de um gabinete da Mulher no Governo Federal, tem dedicado seus esforços para melhorar a posição das mulheres ${ }^{15}$. Estas organizações querem saber mais sobre 0 trabalho e a posição das organizações de mulheres nos Estados Unidos.

Há vários bons exemplos de organização para a mulher que trabalha sob a égide da igreja católica. No Rio, uma Associação de Mulheres Católicas tem uma grande e atraente sala de jantar que serve refeições de baixo custo para a mulher que trabalha no centro da cidade. Lá também há algumas salas de aula, um escritório de serviços de emprego e algumas salas.

A Liga das Mulheres Católicas de São Paulo tem uma sala de jantar menor e diversos outros projetos. Há também outros pequenos exemplos de trabalho.

\footnotetext{
15 Refere-se à Federação Brasileira pelo Progresso Feminino e sua principal liderança, Bertha Lutz que, em 1936, havia se tornado deputada federal. Entre suas atividades na Câmara, destaca-se a criação da Comissão do Estatuto da Mulher.
} 
A YWCA ${ }^{16}$ no Rio de Janeiro tem vários grupos organizados, de educação e classes ginasiais, salas de clube e acampamento de verão para as meninas que trabalham.

Um clube de mulheres chamado União Cívica Feminina em São Paulo possuiu uma escola para meninas em idade de frequentar o curso colegial.

A Federação Brasileira pelo Progresso Feminino há anos vem trabalhando para melhorar a situação das mulheres. As suas líderes estão mais velhas agora e, a menos que uma nova vida e energia entrem para a federação, perderá a sua utilidade real.

A União Universitária Feminina é composta de mulheres jovens universitárias que trabalham em suas profissões. Há organizações de mulheres universitárias em diversas cidades. Elas não são propriamente grupos de "ação", embora exista um grande quadro de lideranças e de inteligência entre elas.

A União das Classes Femininas no Rio de Janeiro tem um grupo interessante de membros - mulheres que são escritoras, que ocupam cargos nos setores privado e públicos, armazéns, etc. Suas ideias são boas, mas não são eficazes.

Há uma associação, no Rio de Janeiro, de jovens mulheres que trabalham que é inteiramente organizada por seus membros e que pertence a "Ação Católica".

\section{CONFIDENCIAL}

\section{BRASIL}

Em conversa com muitas líderes e em visitas feitas em estabelecimentos e instituições que empregam mulheres, certos problemas relacionados com o trabalho feminino eram constantemente enfatizados.

\section{PROBLEMAS DAS MULHERES NA INDÚSTRIA}

Faltas constantes, transferências e aparente ausência de ambição das mulheres nas fábricas têxteis.

Falta de informações estatísticas e analíticas relativas à mulher empregada (números, profissões, condições, etc.); esses dados servem de base para fazer as melhorias necessárias para aumentar a eficiência e a produtividade industrial das mulheres.

Carência de educação e formação profissional para meninas e mulheres que têm que ganhar dinheiro na indústria.

O emprego de menores está intimamente ligado com a carência das escolas especialmente de escolas de educação e formação para meninas e meninos que tenham terminado a escola primária. Escolas para crianças entre 12 e 14 anos ainda é outro problema.

O grande número de meninos e meninas nas fábricas têxteis. Seria interessante e de grande valor investigar os efeitos sobre a saúde de meninas e meninos entre 14 e 18 anos que trabalham 48 horas semanais nas fábricas de algodão. ( 0 chefe da divisão de mulheres e crianças em São Paulo percebe a necessidade).

Ausência de incentivo para as mulheres na indústria, ou seja, promoções, chance de se tornar supervisores, etc. Esse incentivo aumenta a produção.

\footnotetext{
${ }^{16}$ Trata-se da Young Women's Christian Association, em português, a Associação Cristão Feminina do
} Brasil. 
Falta de banheiro limpo e adequado, de sala de repouso e falta de hábitos de higiene entre as mulheres.

Falta de conforto, tais como cadeiras com encostos apropriados, iluminação adequada, se o lugar estiver mobiliado diminuem a fadiga e aumentam a produção.

A não inclusão de meninas em programa de aprendizagem.

Falta de dispositivos de segurança e educação para a segurança.

A noção da direção e do Departamento do Trabalho segundo a qual as mulheres fazem o trabalho mais fácil e, portanto, recebem os mais baixos salários e, por isso, elas se contentam em ganhar o que podem em tais empregos.

Tendência a "proteger" as mulheres na indústria, por causa da maternidade e dos regulamentos de saúde, à despeito de causar desvantagem econômica.

\section{SUGESTÕES}

\section{A. Para assuntos internos}

Convidar Jandyra Rodrigues, de São Paulo para estágio ainda este ano e a senhora Schultz de Belo Horizonte logo em seguida, tão rápido seja possível.

\section{B. Para cooperação contínua}

1. Enviar material para organizações das mulheres e sobre como elas são afetadas por serem mulheres assalariadas. Demonstrar a elas qual a parte que essas organizações tiveram na realização da melhoria das condições das mulheres. Enviar material sobre escolas de formação profissional à Associação Cívica Feminina de São Paulo.

2. Manter o envio de material apropriado aos oficiais do departamento do trabalho sobre saúde e segurança e tarefas que as mulheres podem exercer.

3. Enviar para Dr. Goes e Dr. Mange, ambos do programa de aprendizes, publicações deste país sobre cursos de formação profissional para jovens mulheres e também publicações do programa de Treinamento Por Dentro da Fábrica.

4. Enviar para a escola profissional para meninas em São Paulo o material específico sobre os cursos neste país.

5. Manter contato com o Dr. Del Brito (DASP) sobre cursos de formação para inspetores de fábrica.

6. Enviar material específico para Jandyra Rodrigues de São Paulo, para senhorita Tenoco, do Rio de Janeiro e Senhora Schultz, de Belo Horizonte que são chefes das Divisões de Mulheres e Crianças.

7. Enviar material para as escolas de Serviço Social sobre a preparação e trabalho de gerentes de pessoal, que são mulheres, na indústria e enviar material para as aulas sobre mulheres na indústria, como os de normas de segurança e de saúde, os tipos de trabalho que as mulheres podem fazer, promoções, etc.

C. Para outras agências governamentais

Sugerir Dra. Carlota Queiroz de São Paulo como nossa "distinta convidada" para a Divisão de Relações Culturais do Departamento de Estado. 